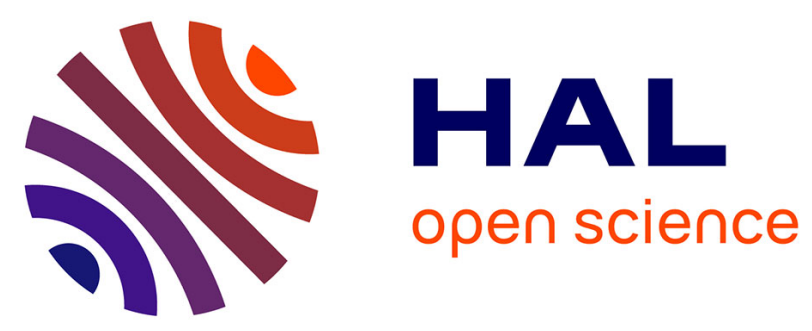

\title{
Photodynamic therapy for actinic keratosis of the forehead and scalp: a randomized, controlled, phase II clinical study evaluating the non-inferiority of a new protocol involving irradiation with a light-emitting, fabric-based device (the Flexitheralight protocol) compared with the conventional protocol involving irradiation with the Aktilite CL 128 lamp. \\ C. Vicentini, Anne-Sophie S Vignion-Dewalle, E Thecua, F. Lecomte, C Maire, P. Deleporte, H. Béhal, D. Kerob, A. Duhamel, Serge Mordon, et al.
}

\section{To cite this version:}

C. Vicentini, Anne-Sophie S Vignion-Dewalle, E Thecua, F. Lecomte, C Maire, et al.. Photodynamic therapy for actinic keratosis of the forehead and scalp: a randomized, controlled, phase II clinical study evaluating the non-inferiority of a new protocol involving irradiation with a light-emitting, fabric-based device (the Flexitheralight protocol) compared with the conventional protocol involving irradiation with the Aktilite CL 128 lamp.. British Journal of Dermatology, In press. hal-01976836

\author{
HAL Id: hal-01976836 \\ https://hal.science/hal-01976836
}

Submitted on 10 Jan 2019

HAL is a multi-disciplinary open access archive for the deposit and dissemination of scientific research documents, whether they are published or not. The documents may come from teaching and research institutions in France or abroad, or from public or private research centers.
L'archive ouverte pluridisciplinaire HAL, est destinée au dépôt et à la diffusion de documents scientifiques de niveau recherche, publiés ou non, émanant des établissements d'enseignement et de recherche français ou étrangers, des laboratoires publics ou privés. 
Photodynamic therapy for actinic keratosis of the forehead and scalp: a randomized, controlled, phase II clinical study evaluating the noninferiority of a new protocol involving irradiation with a light-emitting, fabric-based device (the Flexitheralight protocol) compared with the conventional protocol involving irradiation with the Aktilite CL 128 lamp.

Running head: A new protocol using a light-emitting fabric for PDT of AK.

Manuscript word count: XX

Manuscript table count: 1

Manuscript figure count: 4

C. Vicentini ${ }^{1,2, *}$, AS. Vignion-Dewalle ${ }^{1, *}$, E. Thecua ${ }^{1}$, F. Lecomte ${ }^{1}$, C. Maire ${ }^{1,2}$, P.

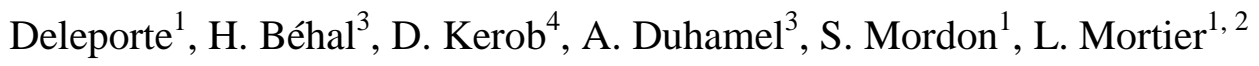

${ }^{1}$ Univ. Lille, INSERM, CHU Lille, U1189 - ONCO-THAI - Image Assisted Laser Therapy for Oncology, F-59000 Lille, France

${ }^{2}$ Department of Dermatology, CHU Lille, F-59000 Lille, France

${ }^{3}$ Univ. Lille, CHU Lille, EA 2694 - Santé Publique: épidémiologie et qualité des soins, Unité de Biostatistiques, F-59000 Lille, France

${ }^{4}$ Galderma International SAS, F-92927 La Défense, France

*Claire Vicentini and Anne-Sophie Vignion-Dewalle contributed equally to this work.

Corresponding author: Anne-Sophie Vignion-Dewalle

INSERM U1189 ONCO-THAI,

1, avenue Oscar Lambret,

F-59037 LILLE Cedex,

France

Tel.: +33 320446717

Fax: +33 320446738

E-mail: anne-sophie.vignion@inserm.fr 


\section{Funding sources:}

This work was supported by the French National Research Agency (ANR) through the Flexitheralight project (Projet-ANR-12-EMMA-0018) (http://www.flexitheralight.com/).

Metvixia cream (168 mg of MAL/g) was graciously supplied by Galderma R\&D (France).

\section{Conflicts of interest:}

Claire Vicentini received travel grants and accommodation expenses to attend the $16^{\text {th }}$ Annual Congress of the European Society for Photodynamic Therapy in Munich, Germany, February 10-11, 2017.

\section{What is already known about this topic?}

- Methyl aminolevulinate photodynamic therapy is an effective and non-invasive treatment for actinic keratosis.

- Treatment-associated pain is frequently experienced by patients treated with the conventional protocol, which requires irradiation with the Aktilite CL 128 lamp.

- Photodynamic therapy using daylight as the activating light source has been confirmed as equally effective and less painful than the conventional protocol, but it cannot be performed in all weather conditions.

\section{What does this study add?}

- This study demonstrates that the Flexitheralight protocol, which can be performed in all weather conditions, is equally effective as the conventional photodynamic therapy protocol for actinic keratosis and is a less painful technique. 


\begin{abstract}
Background: Photodynamic therapy is an effective treatment for actinic keratosis, particularly for patients with large areas of field cancerization. Among the approved protocols in Europe, the most widely used requires irradiation with the Aktilite CL 128 lamp. However, pain during irradiation and the suboptimal adaptability of the lamp relative to the treatment area are two limiting factors of this protocol. To overcome these limits, a new protocol (referred to as the Flexitheralight protocol) involving irradiation with a light-emitting, fabricbased device was developed.
\end{abstract}

Objectives: This paper aims to assess the non-inferiority, in terms of photodynamic therapy efficacy for treating actinic keratosis, of the Flexitheralight protocol compared with the conventional protocol, which requires irradiation with the Aktilite CL 128 lamp.

Methods: A monocentric, randomized, controlled, phase II clinical study was performed. Twenty-five patients with grade I-II actinic keratoses of the forehead and scalp were treated with methyl aminolevulinate photodynamic therapy in two symmetrical areas. One area was treated with the conventional protocol ( $\mathrm{n}=154$ actinic keratoses), whereas the other area was treated with the Flexitheralight protocol ( $n=156$ actinic keratoses). The primary endpoint was the lesion complete response rate at three months (an absolute non-inferiority margin of $-10 \%$ was used). The secondary endpoints included patient-reported pain at the end of the irradiation.

Results: At three months, the lesion complete response rate with the Flexitheralight protocol was non-inferior to that obtained with the conventional protocol $(66.0 \%$ vs. $59.1 \%$, respectively; absolute difference, $6.9 \%$; $95 \%$ confidence interval, $-0.6 \%$ to $14.5 \%$ ). Patientreported pain was significantly lower with the Flexitheralight protocol than with the conventional protocol (mean \pm standard deviation: $0.4 \pm 0.6$ vs. $5.0 \pm 2.6 ; p<0.0001$ ).

Conclusions: The Flexitheralight protocol is non-inferior in terms of efficacy and superior in terms of tolerability to the conventional protocol for treating actinic keratoses of the forehead and scalp.

Trial registration: ClinicalTrials.gov identifier: NCT03076918. 


\section{Introduction}

Visible actinic keratoses (AK) are often associated with subclinical lesions on the surrounding skin, resulting in areas of field cancerization ${ }^{1,2}$. Photodynamic therapy (PDT) using 5aminolevulinic acid nanoemulsion (BF-200-ALA) (BF-200-ALA-PDT) or methyl aminolevulinate (MAL) (MAL-PDT) is an effective therapeutic option to treat AK and field cancerization $^{2-6}$. Topical application of BF-200-ALA or MAL induces selective accumulation of the photosensitizer protoporphyrin IX (PpIX) in AK; subsequent PpIX activation by specific wavelengths of light generates reactive oxygen species, which causes tissue injury and AK destruction ${ }^{7}$.

In Europe, activation with red light using the Aktilite CL 128 (Galderma SA, Lausanne, Switzerland) and a total light dose of $37 \mathrm{~J} / \mathrm{cm}^{2}$ after 3 hours of incubation with MAL is the conventional PDT protocol used to treat AK ${ }^{8-10}$. Although effective ${ }^{8-10}$, this protocol (hereafter referred to as C-PDT) is known to be painful, and concurrent use of cold air analgesia, hypnosis, and local anaesthesia with nerve blocks may be required to relieve discomfort and pain ${ }^{9,10}$.

Recently, several protocols applying irradiation with daylight have been reported to be equally as effective as C-PDT. Because a maximum of 30 minutes was allowed for MAL incubation, allowing continuous activation of small amounts of PpIX, these protocols are better tolerated by patients than C-PDT ${ }^{11-16}$. Nonetheless, using daylight as the irradiation source is not realistic for all weather conditions (e.g., different temperatures or rain, among others) ${ }^{17}$ and is also not suitable for all patients or all anatomical sites. Furthermore, the dermatologist is unable to control the total light dose.

The Flexitheralight protocol, developed within the Flexitheralight project supported by the French National Research Agency (ANR) (Projet-ANR-12-EMMA-0018) (http://www.flexitheralight.com/), uses a 30-minute MAL incubation followed by $2.5 \mathrm{~h}$ of irradiation with a light-emitting, fabric-based device. Due to the short incubation time, the Flexitheralight protocol (FLEXI-PDT) provides a nearly pain-free, year-round alternative to C-PDT. Moreover, the high flexibility of the light-emitting, fabric-based device ensures optimal adaptability to the treatment area, offering clear advantages over other protocols. 
The aim of this study was to assess the efficacy and tolerability of FLEXI-PDT compared to C-PDT for treating patients with AK on the forehead and scalp. The primary hypothesis was that FLEXI-PDT was non-inferior to C-PDT in terms of lesion complete response rate at three months.

\section{Patients and methods}

\section{A. Study design}

This study was a monocentric, randomized, controlled, non-inferiority, phase II clinical study that compared two PDT protocols to treat AK.

This study was performed in accordance with the ethical principles of the Declaration of Helsinki (2008) and the International Conference on Harmonisation - Good Clinical Practices (ICH-GCP) and in compliance with article L. 1121-4 of the French Public Health Code. The study design was reviewed and approved by the French National Agency for the Safety of Medicines and Health Products (ANSM) (authorization number: 2013-A01096-39) and the French Ethics Committee (CPP) (authorization number: CPP-03/051/2013).

\section{B. Patients}

Patients aged 18 years or older with 10 to 14 non-pigmented grade I or II AK lesions on the forehead and/or scalp were recruited from patients referred to the Department of Dermatology, Lille University Hospital. Patients with clinically diagnosed AK that were symmetrically distributed over the forehead and/or scalp were enrolled and treated from September 2014 to January 2017 and followed for six months. All of the patients gave written informed consent before entering the study, which is registered at ClinicalTrials.gov (Identifier: NCT03076918).

The exclusion criteria included pregnancy; immunosuppression; use of topical corticosteroids within the last 2 weeks; use of cryotherapy, curettage or PDT within the last 30 days; use of topical or systemic retinoids, urea, alpha-hydroxy acids, chemotherapy or immunotherapy within the last four weeks; use of topical ingenol mebutate, 5-fluoro-uracil, imiquimod or diclofenac within the last 3 months; contra-indication to PDT and patients included in a clinical trial within the last 30 days. 
At the screening visit, each patient's demographic characteristics, medical history, current medications and Fitzpatrick skin type were recorded, and a physical examination including general appearance, regional lymph nodes and dermatologic examination of the skin was performed.

Follow-up visits were scheduled at 7 days, 3 months and 6 months.

\section{The Flexitheralight protocol}

FLEXI-PDT, which includes a 30-minute incubation with MAL cream under transparent occlusive dressing (Tegaderm, 3M, London Ontario, Canada), applies irradiation with a lightemitting, fabric-based device without removing the transparent occlusive dressing. As illustrated in Figure 1, this device consists of a power and control unit including three $5 \mathrm{~W}$ laser diodes, each connected to a flexible, light-emitting fabric sample of size $21.5 \mathrm{~cm} \times 5 \mathrm{~cm}$ that is made of biocompatible optical fibres ${ }^{18}$. The fabric samples, which were sewn together (total area: $3 \times 21.5 \mathrm{~cm} \times 5 \mathrm{~cm}=322.5 \mathrm{~cm}^{2}$ ), sequentially emit $635 \mathrm{~nm}$ red light at a low fluence rate $\left(12.3 \mathrm{~mW} / \mathrm{cm}^{2}\right)$ for one minute, such that fractionated irradiation (1 minute of light, 2 minutes of darkness) is achieved. An irradiation time of two and a half hours delivers a total light dose of approximately $37 \mathrm{~J} / \mathrm{cm}^{2}$ anywhere in the treated area $\left(12.3 \mathrm{~mW} / \mathrm{cm}^{2} \times\right.$ $9000 \mathrm{~s} \times 1$ minute of light / ( 1 minute of light +2 minutes of darkness $))$. The device has been tested and classified into the exempt risk group in accordance with IEC 60601-2-57/2012. FLEXI-PDT has two main features. First, the short incubation time should allow for continuous activation of small amounts of porphyrins during their formation and reduced patient-reported pain, similarly to protocols in which irradiation is applied using daylight. In addition, the fabrics are flexible and allow optimal adaptability to the treatment area, providing more homogeneous irradiation than that delivered by standard rigid light sources. 


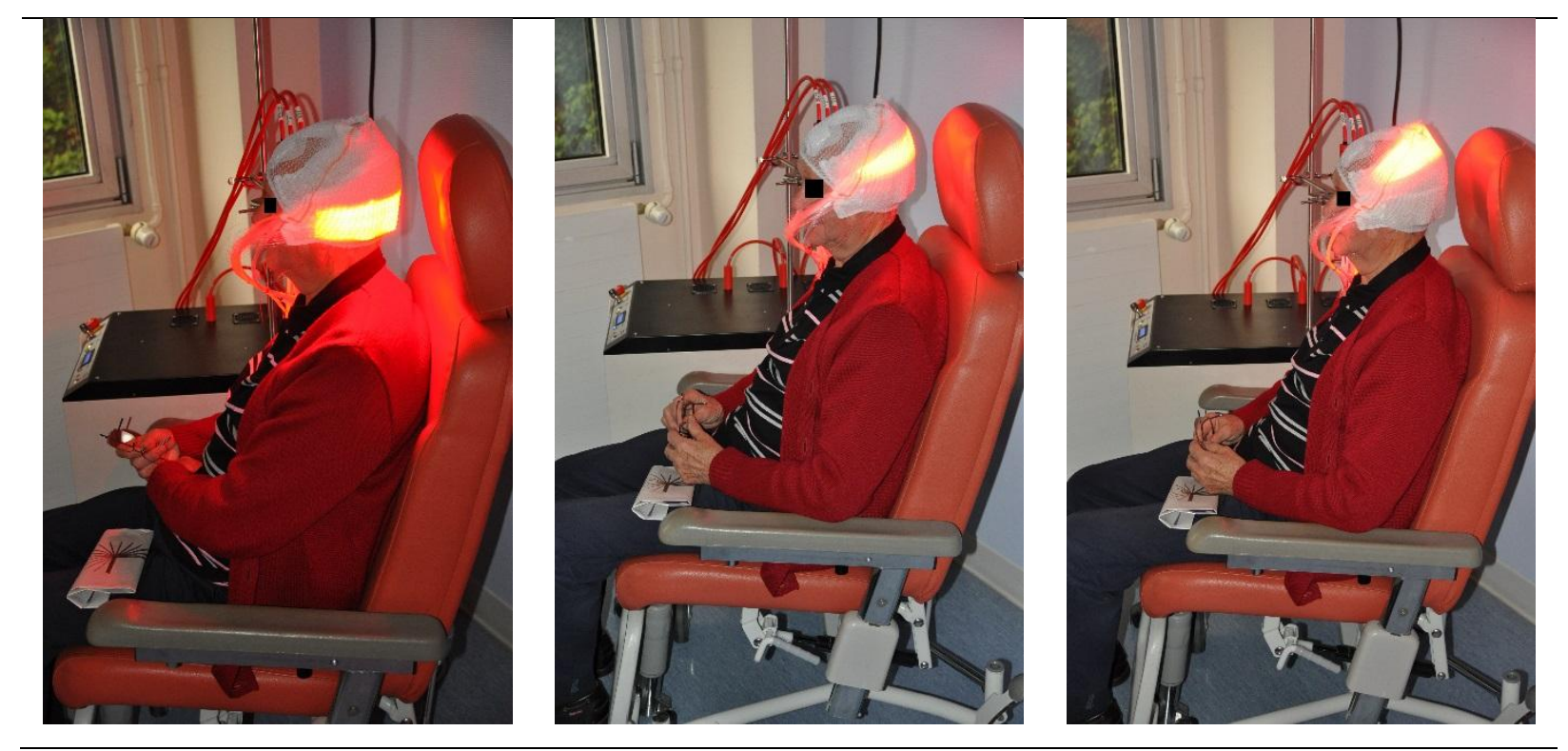

Figure 1: The three flexible, light-emitting optical fibre-based fabrics used for FLEXI-PDT sequentially emit $635 \mathrm{~nm}$ red light for 1 minute, resulting in fractionated irradiation (1 minute of light, 2 minutes of darkness).

\section{Treatment}

The treatment regimen included one mandatory PDT session and a second identical session if at least one $\mathrm{AK}$ (among the included $\mathrm{AK}$ ) remained at three months after the first PDT session. This second PDT session was performed within the three weeks following the 3month follow-up visit.

For each patient on the day of treatment, AK lesions were graded, photographed and divided into two areas, with both the same number of lesions and the same grades of lesions in each area. The protocol used for each area was assigned according to randomization.

The two areas were prepared by removing crusts and gently scraping the lesion surface. Approximately 2 to $4 \mathrm{~g}$ of MAL cream (Metvixia, Galderma) was applied in a $1 \mathrm{~mm}$ thick layer to the lesions and the surrounding normal skin (5-10 $\mathrm{mm}$ margin) of both areas. The area randomized to receive FLEXI-PDT was covered with a transparent occlusive dressing (Tegaderm, 3M, London Ontario, Canada), whereas both a transparent occlusive dressing (Tegaderm, 3M, London Ontario, Canada) and a lightproof dressing (aluminium foil) were applied over the area randomized to receive C-PDT. The light-emitting, fabric-based device used for FLEXI-PDT was immediately applied to the corresponding assigned area. After 30 minutes, the device was switched on, and irradiation was performed. Two and a half hours 
later, the treatment was completed, and the treated area was protected with aluminium foil. MAL was then removed from the area randomized to receive C-PDT with a saline solution. Finally, the Aktilite CL 128 was placed between 8 and $10 \mathrm{~cm}$ from the area to be treated (illumination surface of the Aktilite CL 128: $144 \mathrm{~cm}^{2}$ ) and was programmed to deliver 37 $\mathrm{J} / \mathrm{cm}^{2}$ over 10 minutes.

\section{E. Randomization}

The randomization schedule was generated by the statistician using the PROC PLAN procedure of SAS (SAS Institute Inc., Cary, North Carolina, USA) with a 1:1 allocation ratio and a block size of six. Allocation was concealed using sequentially numbered, opaque, sealed envelopes that were opened sequentially by the investigator at the beginning of the treatment.

\section{F. Endpoints}

The primary endpoint was the lesion complete response rate at three months. Lesion response (complete response vs. incomplete response) was clinically assessed by the investigator. Lesion localization was performed using photographs taken on the day of treatment (before treatment).

The secondary endpoints were multiple and included evaluation of treatment tolerability at the end of irradiation, evaluation of lesion complete response rate at six months, evaluation of cosmetic outcome at three and six months, estimation of the number of patients with AK reduction higher than $75 \%$ at three and six months, and evaluation of patient satisfaction seven days after treatment. Adverse events and pain were used as criteria for treatment tolerability. Pain was assessed using a visual analogue scale (0: no pain, 10: worst pain). The cosmetic outcome was evaluated as "excellent", "good", "fair", or "poor" using a standardized scale. Patient satisfaction was assessed with a standard questionnaire.

\section{G. Data analysis}

The study was designed to have a statistical power of $80 \%$ with a one-sided alpha level of 0.025 to demonstrate non-inferiority in terms of lesion complete response rate at three months 
of FLEXI-PDT compared to C-PDT. A split-cluster design was adopted, and a design effect was assumed for the sample size calculation to account for both the correlation between lesions within the same patient (cluster) (intra-cluster correlation (ICC) of 0.011) and the correlation between lesions within the same area (period) (inter-period correlation (IPC) of 0.0022). Assuming a mean lesion number per patient per area of six (which, with the aboveset ICC and IPC, led to a design effect of 1.0528), a lesion complete response rate of $75 \%$ in both areas, and an absolute non-inferiority margin of $-10 \%$, the number of required lesions per area was 245. This corresponds, based on the above-assumed six lesions per patient per area, to 42 patients.

Continuous variables were expressed as the mean and standard deviation (SD), and categorical variables were expressed as the frequency and percentage. The normality of the distribution was assessed graphically and using the Shapiro-Wilk test.

The non-inferiority of FLEXI-PDT compared to C-PDT was assessed by estimating a twosided $95 \%$ confidence interval of the absolute difference in lesion complete response rates at three months. This estimation was performed using a generalized estimating equation (GEE) model with a binomial distribution and identity link function to account for repeated measures from individual patients. Treatment area was included as a covariate. If the lower limit of the 95\% confidence interval was high than the pre-stated absolute margin of non-inferiority, FLEXI-PDT was declared non-inferior to C-PDT, and a two-sided superiority test was performed at an alpha level of 0.05 .

The two-sided $95 \%$ confidence interval of the absolute difference in lesion complete response rates at six months between FLEXI-PDT and C-PDT was estimated using the GEE model as above. Depending on the lower limit of this confidence interval, declaration of non-inferiority at six months and a subsequent superiority test were performed.

The difference between FLEXI-PDT and C-PDT in pain levels reported at the end of each protocol was assessed using a linear mixed model with patients as random effects (the significance level was set at a two-sided alpha level of 0.05).

Finally, the difference between FLEXI-PDT and C-PDT regarding the rates of patients with at least $75 \%$ reduction in $\mathrm{AK}$ at three and six months was assessed using the GEE model to 
account for intra-patient correlation among areas (the significance level was set at a two-sided alpha level of 0.05).

All of the statistical analyses were performed using SAS software version 9.4 (SAS Institute Inc., Cary, North Carolina, USA).

\section{Results}

\section{A. Population study}

Twenty-seven patients were enrolled in the study. Two patients dropped out for personal reasons before treatment, resulting in a final study sample of 25 patients. These 25 patients with a total of $310 \mathrm{AK}$ lesions underwent treatment and were examined three months after treatment. The ICC and IPC were estimated to be 0.08 and 0.036 , respectively. Due to 116 remaining AK, a second treatment session was required for 20 patients who had exhibited a total of $252 \mathrm{AK}$ at the first treatment session. This second treatment session was performed within the three weeks following the 3-month follow-up visit. Between three and six months following the first treatment session, one patient dropped out due to a serious adverse event not related to the treatment, and one patient did not return for the 6-month visit for personal reasons. Therefore, twenty-three patients with 286 AK lesions completed the study at 6 months. The study flow diagram is shown in Figure 2.

Patient and lesion characteristics are reported in Table 1. All of the treated patients were men with a mean age of 70.6 years (range, 51 to 87); most had phototype II (76.0\%). A total of 156 AK lesions, $42.9 \%$ and $57.1 \%$ of which were grade I or II, respectively, were treated with FLEXI-PDT. Overall, 154 AK lesions (grade I: 42.9\%; grade II: 57.1\%) received C-PDT. 


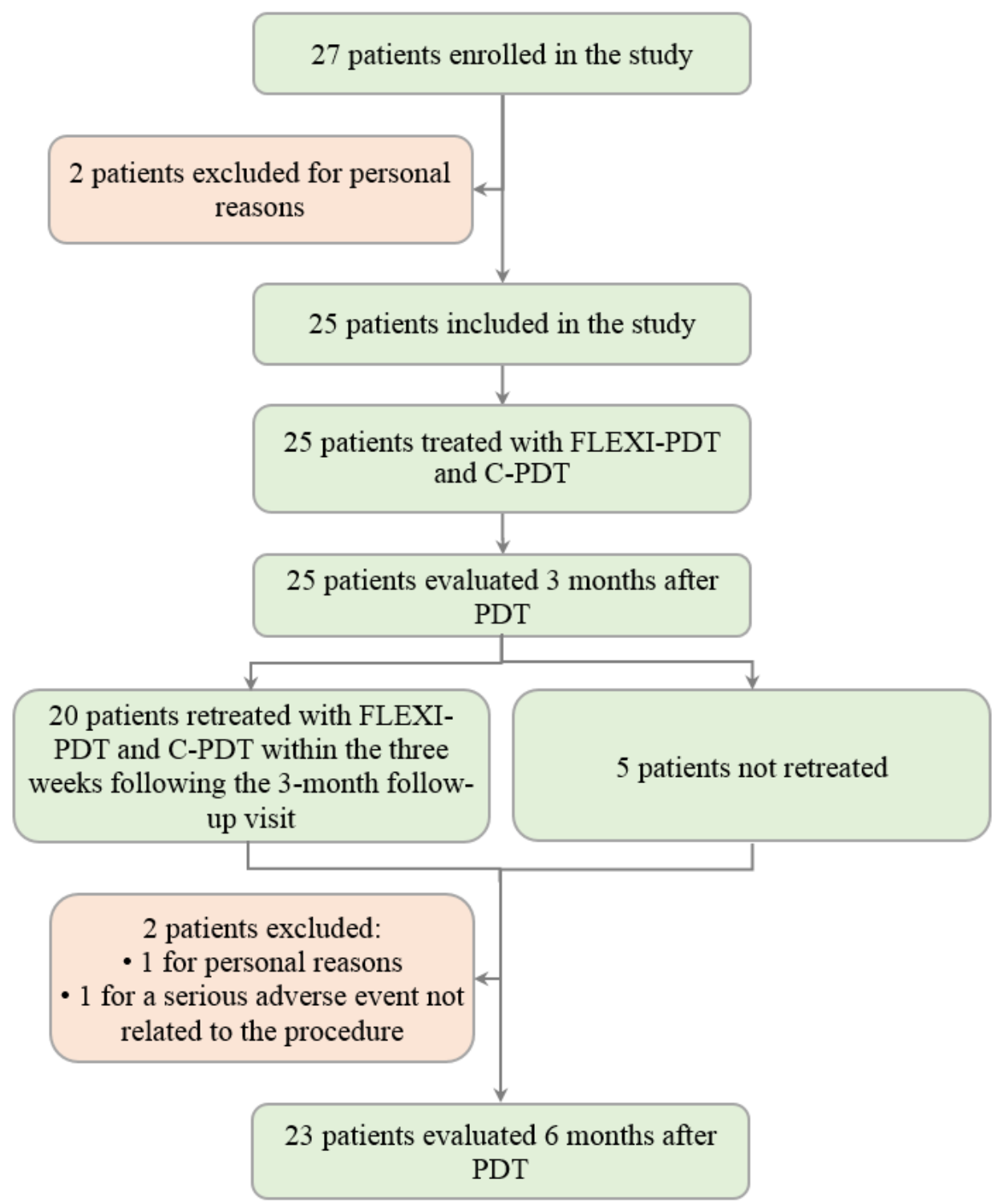

Figure 2: Study flow diagram (SCC: Squamous cell carcinoma)

Table 1: Demographics and clinical characteristics on the day of treatment.

Total $(\mathrm{n}=25)$

\begin{tabular}{cl}
\hline Age (years) & \\
Mean \pm SD & $70.6 \pm 9.7$ \\
Range & $51-87$ \\
\hline Sex (\%) & \\
Male & $25(100.0)$ \\
Female & $0(0.0)$ \\
\hline
\end{tabular}

Fitzpatrick skin phototype (\%) 


\begin{tabular}{lll}
\hline \hline & FLEXI-PDT & C-PDT \\
\hline $\begin{array}{l}\text { Number of total treated AK } \\
\text { lesions }\end{array}$ & 156 & 154 \\
\hline $\begin{array}{l}\text { Severity of total treated } \\
\text { lesions (\%) }\end{array}$ & \\
\multicolumn{1}{c}{ Grade I } & $67(42.9)$ & $66(42.9)$ \\
Grade II & $89(57.1)$ & $88(57.1)$ \\
\hline
\end{tabular}

\section{B. Efficacy}

With $91 \mathrm{AK}$ lesions exhibiting a complete response and $63 \mathrm{AK}$ lesions showing an incomplete response, C-PDT achieved a lesion complete response rate of $59.1 \%$ at three months, which is lower than the 66.0\% achieved with FLEXI-PDT (absolute difference, $6.9 \%$; $95 \%$ confidence interval, $-0.6 \%$ to $14.5 \%$ ). Because the lower limit was above the prestated absolute margin of non-inferiority (-10\%), the non-inferiority of FLEXI-PDT compared to C-PDT was supported (Figure 3). However, with a p-value of 0.07, FLEXI-PDT was not superior to C-PDT, in terms of efficacy at three months.

Six months following treatment, the lesion complete response rate achieved for the 23 patients who completed the study (286 AK lesions) was $84.0 \%$ with FLEXI-PDT vs. $76.8 \%$ with CPDT (absolute difference, $7.2 \%$; $95 \%$ CI $-1.0 \%$ to $15.4 \%$ ). The non-inferiority of FLEXIPDT compared to C-PDT was therefore demonstrated, although the superiority test was not significant $(\mathrm{p}=0.09)$ (Figure 3).

The response rate at six months was approximately 1.3 times higher than that at three months for both FLEXI-PDT and C-PDT.

Regarding the rates of patients with at least $75 \%$ reduction in $\mathrm{AK}$, there was no significant difference between the two protocols at three months $(\mathrm{p}=0.71)$ or six months $(\mathrm{p}=1.00)$. 


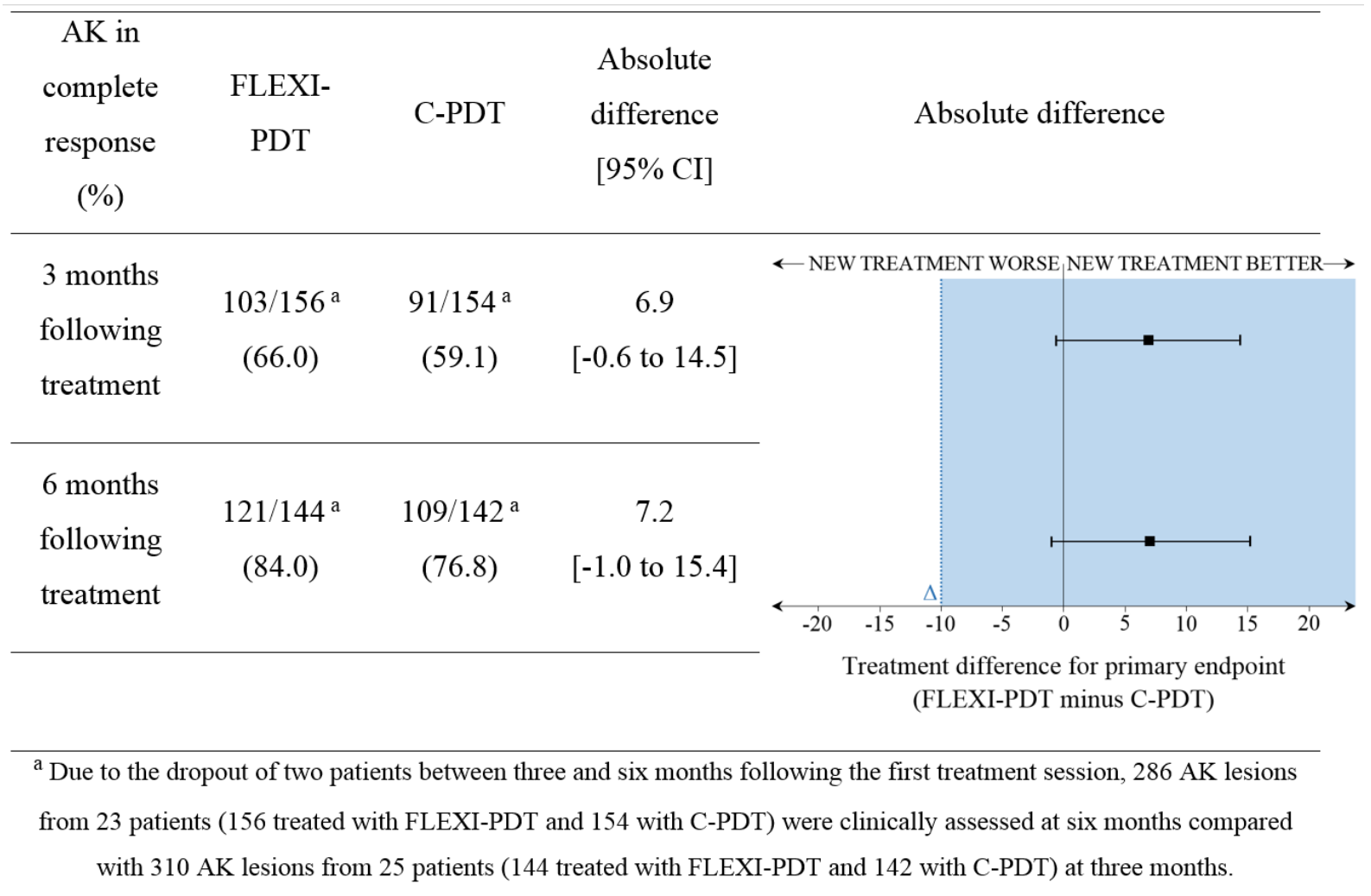

Figure 3: AK lesion complete response comparing FLEXI-PDT and C-PDT. The absolute

differences in lesion complete response rates between FLEXI-PDT and C-PDT and the associated 95\% confidence intervals (CI) were estimated from the GEE model, accounting for repeated measures from individual patients and including treatment area as a covariate. Error

bars indicate the two-sided 95\% CI. The blue dashed line indicates the absolute noninferiority margin, while the blue tinted region indicates the zone of inferiority.

\section{Tolerability}

\section{Pain}

As shown in Figure 4, the patient-reported pain level at the end of irradiation was significantly lower (almost non-existent) for FLEXI-PDT (mean \pm SD: $0.4 \pm 0.6$ for the first treatment session and $0.2 \pm 0.5$ for the second) than for C-PDT (mean \pm SD: $5.0 \pm 2.6$ for the first treatment session and $5.0 \pm 2.2$ for the second) $(\mathrm{p}<0.0001$ for both treatment sessions). 


\section{Pain levels}

a) First treatment session b) Second treatment session

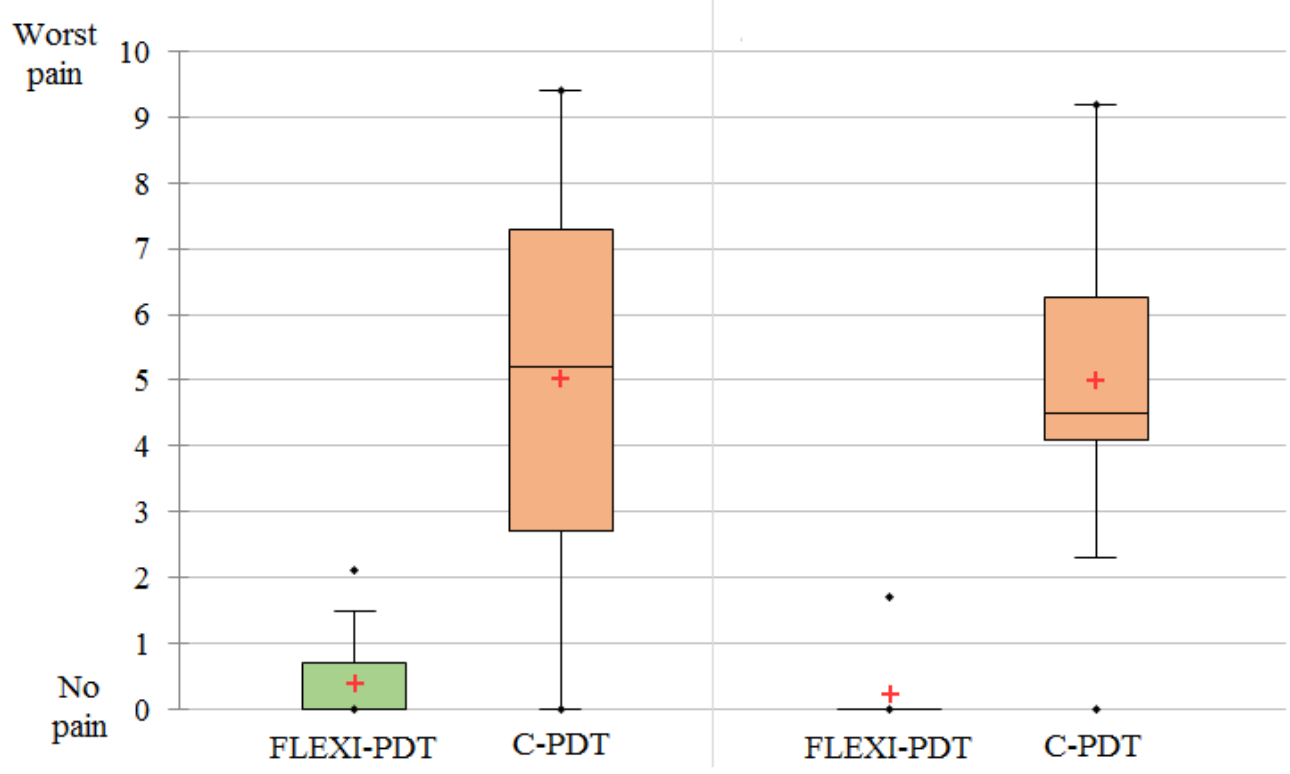

Figure 4: Box plot of pain levels. The red crosses correspond to the mean pain levels, and the central horizontal bars are the median pain levels. The lower and upper limits of the boxes are the first and third quartiles, respectively. Points above or below the upper and lower bounds of the whiskers can be considered outliers. The ends of the whiskers represent the minimum and maximum pain levels when excluding outliers.

\section{Adverse events}

Similar local side effects, such as erythema and oedema, were observed with both FLEXIPDT and C-PDT. In dermatological PDT practice, these effects typically do not require special care.

One patient experienced scalp impetiginisation caused by Staphylococcus aureus in both areas 2 days after treatment. Neither fever nor adenopathy were detected. This grade I adverse event was treated with systemic antibiotic therapy.

One patient with multiple risk factors for retinal detachment and a history of retinal detachment experienced retinal detachment in one eye a few minutes after the beginning of FLEXI-PDT. This adverse event was reported by the patient only at the end of FLEXI-PDT during the completion of the questionnaire about satisfaction. The evolution was favourable 
with resolution of the detachment by laser therapy and partial recovery of visual acuity. No relation between this grade III adverse event and the treatment was found.

One patient with ischaemic heart disease, high blood pressure and diabetes had heart and kidney failure a few days after the three-month follow-up visit; therefore, neither the second treatment session nor the six-month follow-up visit were performed. No relation between this grade IV adverse event and the study was assumed.

\section{Cosmetic outcome and patient satisfaction}

For each patient evaluated, the cosmetic outcomes three or six months following treatment were identical for both protocols. Three months following treatment, the overall cosmetic outcome was good in almost two-thirds of patients (62.5\%), fair in one-third of patients $(33.3 \%)$ and excellent in one patient $(4.2 \%)$. A higher rate of patients with an excellent cosmetic outcome (13.1\%) was achieved at the 6-month follow-up visit, while the rates of patients with fair or good cosmetic outcomes were slightly lower $(30.4 \%$ and $56.5 \%$, respectively).

Including all protocols, 13/23 (56.5\%) patients were very satisfied with the treatment, 9/23 (39.1\%) patients were satisfied, and 1/23 (4.4\%) patient was very dissatisfied. Two patients did not respond to the questionnaire.

Of the 24 patients who responded to the treatment choice question, $15(62.5 \%)$ preferred FLEXI-PDT, three (12.5\%) preferred C-PDT, and six patients (25\%) expressed no preference.

\section{Discussion}

In this study, we demonstrated that FLEXI-PDT was significantly non-inferior to C-PDT for treating AK of the forehead and scalp. FLEXI-PDT showed a lesion complete response rate at three months of $66.0 \%$ vs. $59.1 \%$ for C-PDT. Moreover, we found that FLEXI-PDT was significantly better tolerated than C-PDT, particularly in terms of patient-reported pain (mean patient-reported pain: 0.4 for FLEXI-PDT vs. 5.0 for C-PDT). 
Based on studies that found no association between the complete response rate and irradiance 19,20 , FLEXI-PDT, with a light dose $\left(37 \mathrm{~J} / \mathrm{cm}^{2}\right)$ equal to C-PDT and an irradiance $(12.3$ $\mathrm{mW} / \mathrm{cm}^{2}$ ) more than five times lower ${ }^{21}$, was expected to be non-inferior to C-PDT. The light dose delivery method might even boost FLEXI-PDT into superiority over C-PDT. Indeed, FLEXI-PDT combines two features that have been demonstrated to improve the efficacy of PDT to treat AK. On the one hand, there is fractionated irradiation, which allows the reoxygenation of tissues and photosensitizer relocalization during the dark periods and reperfusion injury with the release of free radicals causing tissue damage during light periods ${ }^{22-24}$. On the other hand, the flexible, light-emitting fabric exhibits optimal adaptability to the area to be treated, which results in more homogeneous irradiation than that delivered by standard rigid light sources such as the Aktilite CL 128 lamp used in C-PDT ${ }^{25}$. Despite these two features, FLEXI-PDT unfortunately demonstrated no significant superiority. Nonetheless, p-values for superiority, which are slightly higher than 0.05 , can be accepted as representing a tendency to superiority for FLEXI-PDT and indicate the need for additional study with more patients.

Furthermore, with a short MAL incubation of 30 minutes and a low irradiance of 12.3 $\mathrm{mW} / \mathrm{cm}^{2}$, FLEXI-PDT allows for a balance between the development and photodegradation of PpIX (the PpIX molecules are photoactivated/photodegraded as quickly as they are formed), thus ensuring low PpIX accumulation. This low accumulation reduces patientreported pain and enables FLEXI-PDT to be nearly pain-free (mean patient-reported pain: 0.4) without the use of strategies to cope with pain, similar to protocols involving irradiation with daylight ${ }^{11-16}$. However, in contrast to those protocols, FLEXI-PDT can be conducted in all weather conditions, in any geographic location, and year-round (subject to sufficient temperature) and always delivers a light dose of $37 \mathrm{~J} / \mathrm{cm}^{2}$. FLEXI-PDT could become the treatment of choice for AK, particularly for patients with large field cancerization, as the size of the treated area is the strongest pain predictor, and the most sensitive areas to treat include the face and the scalp ${ }^{26}$.

The lesion complete response rate at three months for C-PDT, which was $59.1 \%$ in this study, is lower than most rates reported in the literature, which usually range from $70 \%$ to $90 \%{ }^{8-}$ 10,14,16,27. This lower lesion complete response rate can be explained by the difference in AK grade across studies; in the present study, $57.1 \%$ of AK were grade II, whereas most previous studies ${ }^{8,9,14,16}$ involved a large majority of grade I AK, which are known to exhibit better 
response to MAL-PDT than grade II AK ${ }^{8,10,28}$. The use of multiple treatment sessions to increase treatment efficiency, as in previous studies ${ }^{9,10}$, may also have contributed to this difference in the lesion complete response rate. Nevertheless, other studies (on the current use of MAL-PDT in France ${ }^{29}$ or performed by Kessels et al. ${ }^{30}$ ) have shown similar "low" lesion complete response rates for C-PDT.

Due to the initiation of the PHOS-ISTOS clinical study (ClinicalTrials.gov Identifier: NCT03076892) that aimed to assess the non-inferiority of the PHOS-ISTOS protocol compared to C-PDT, this study was stopped earlier than planned. Like FLEXI-PDT, the PHOS-ISTOS protocol is a protocol for PDT that applies irradiation with a light-emitting fabric-based device to treat AK. However, compared to FLEXI-PDT, the device is more compact, and the illumination parameters (irradiance: $1.3 \mathrm{~mW} / \mathrm{cm}^{2}$; light dose: $12 \mathrm{~J} / \mathrm{cm}^{2}$; irradiation time: 2 h 30) are different. Given the premature termination of the Flexitheralight study, only 25 patients were included instead of the planned 42. Although this reduction in sample size resulted in a reduction in the a priori statistical power of the study for the primary endpoint, our sample of 25 patients was sufficient to demonstrate the statistical non-inferiority and higher tolerability of FLEXI-PDT compared with C-PDT. Nevertheless, this reduction in statistical power may have led to upward-biased estimates of the treatment effect. In addition to avoiding the risk of biased estimates, the recruitment of more patients might have allowed us to demonstrate the above-discussed superiority of FLEXI-PDT to C-PDT.

The use of the light-emitting, fabric-based device has already been extended to PDT treatment for vulvar Paget's disease ${ }^{31}$. This extension was motivated by the low pain levels experienced by patients during FLEXI-PDT, and extension to other medical indications is currently under investigation.

\section{Conclusion}

This randomized controlled clinical study demonstrated that PDT using the Flexitheralight protocol is non-inferior to PDT using the conventional protocol in terms of efficacy at three months and is better tolerated. Furthermore, PDT using the Flexitheralight protocol can be performed in all weather conditions, in any geographic location, year-round and could therefore become the treatment of choice for AK. 



\section{References}

1 Ibrahim SF, Brown MD. Actinic keratoses: a comprehensive update. J Clin Aesthet Dermatol 2009; 2: 43-8.

2 Szeimies RM, Torezan L, Niwa A et al. Clinical, histopathological and immunohistochemical assessment of human skin field cancerization before and after photodynamic therapy. $\mathrm{Br} J$ Dermatol 2012; 167: 150-9.

3 Braathen LR, Szeimies RM, Basset-Seguin N et al. Guidelines on the use of photodynamic therapy for nonmelanoma skin cancer: an international consensus. International Society for Photodynamic Therapy in Dermatology, 2005. J Am Acad Dermatol 2007; 56: 125-43. Morton CA, McKenna KE, Rhodes LE et al. Guidelines for topical photodynamic therapy: update. Br J Dermatol 2008; 159: 1245-66.

5 Morton C, Szeimies RM, Sidoroff A et al. European Dermatology Forum Guidelines on topical photodynamic therapy. Eur J Dermatol 2015; 25: 296-311.

6 Wiegell SR. Update on photodynamic treatment for actinic keratosis. Curr Probl Dermatol 2015; 46: 122-8.

$7 \quad$ Plaetzer K, Krammer B, Berlanda J et al. Photophysics and photochemistry of photodynamic therapy: fundamental aspects. Lasers Med Sci 2009; 24: 259-68.

8 Morton C, Campbell S, Gupta G et al. Intraindividual, right-left comparison of topical methyl aminolaevulinate-photodynamic therapy and cryotherapy in subjects with actinic keratoses: a multicentre, randomized controlled study. Br J Dermatol 2006; 155: 1029-36.

9 Pariser $\mathrm{D}$, Loss $\mathrm{R}$, Jarratt $\mathrm{M}$ et al. Topical methyl-aminolevulinate photodynamic therapy using red light-emitting diode light for treatment of multiple actinic keratoses: A randomized, double-blind, placebo-controlled study. J Am Acad Dermatol 2008; 59: 569-76.

Szeimies RM, Matheson RT, Davis SA et al. Topical methyl aminolevulinate photodynamic therapy using red light-emitting diode light for multiple actinic keratoses: a randomized study. Dermatol Surg 2009; 35: 586-92.

11 Wiegell SR, Fabricius S, Gniadecka M et al. Daylight-mediated photodynamic therapy of moderate to thick actinic keratoses of the face and scalp: a randomized multicentre study. $\mathrm{Br}$ J Dermatol 2012; 166: 1327-32.

12 Wiegell SR, Fabricius $S$, Stender IM et al. A randomized, multicentre study of directed daylight exposure times of $1(1 / 2)$ vs. $2(1 / 2) \mathrm{h}$ in daylight-mediated photodynamic therapy with methyl aminolaevulinate in patients with multiple thin actinic keratoses of the face and scalp. Br J Dermatol 2011; 164: 1083-90.

13 Wiegell SR, Haedersdal M, Eriksen P et al. Photodynamic therapy of actinic keratoses with 8\% and $16 \%$ methyl aminolaevulinate and home-based daylight exposure: a double-blinded randomized clinical trial. Br J Dermatol 2009; 160: 1308-14.

14 Wiegell SR, Haedersdal M, Philipsen PA et al. Continuous activation of PpIX by daylight is as effective as and less painful than conventional photodynamic therapy for actinic keratoses; a randomized, controlled, single-blinded study. Br J Dermatol 2008; 158: 740-6.

15 Wiegell SR, Wulf HC, Szeimies RM et al. Daylight photodynamic therapy for actinic keratosis: an international consensus: International Society for Photodynamic Therapy in Dermatology. J Eur Acad Dermatol Venereol 2012; 26: 673-9.

16 Rubel DM, Spelman L, Murrell DF et al. Daylight photodynamic therapy with methyl aminolevulinate cream as a convenient, similarly effective, nearly painless alternative to conventional photodynamic therapy in actinic keratosis treatment: a randomized controlled trial. Br J Dermatol 2014; 171: 1164-71. 
Wiegell SR, Fabricius S, Heydenreich J et al. Weather conditions and daylight-mediated photodynamic therapy: protoporphyrin IX-weighted daylight doses measured in six geographical locations. Br J Dermatol 2013; 168: 186-91.

18 Cochrane C, Mordon SR, Lesage JC et al. New design of textile light diffusers for photodynamic therapy. Mater Sci Eng C Mater Biol Appl 2013; 33: 1170-5. Langmack K, Mehta R, Twyman P et al. Topical photodynamic therapy at low fluence rates-theory and practice. J Photochem Photobiol B 2001; 60: 37-43.

20 Apalla Z, Sotiriou E, Panagiotidou D et al. The impact of different fluence rates on pain and clinical outcome in patients with actinic keratoses treated with photodynamic therapy. Photodermatol Photoimmunol Photomed 2011; 27: 181-5.

21 GALDERMA. Tailored for PDT - Galderma. Available at: http://www.galderma.se/Portals/3/images/2014/files/Brochure\%204p_AKTILITE_201303.pdf 2013.

22 Curnow A, Haller JC, Bown SG. Oxygen monitoring during 5-aminolaevulinic acid induced photodynamic therapy in normal rat colon. Comparison of continuous and fractionated light regimes. J Photochem Photobiol B 2000; 58: 149-55.

23 de Haas ER, de Vijlder HC, Sterenborg HJ et al. Fractionated aminolevulinic acidphotodynamic therapy provides additional evidence for the use of PDT for non-melanoma skin cancer. J Eur Acad Dermatol Venereol 2008; 22: 426-30.

24 Sotiriou E, Apalla Z, Chovarda E et al. Single vs. fractionated photodynamic therapy for face and scalp actinic keratoses: a randomized, intraindividual comparison trial with 12-month follow-up. J Eur Acad Dermatol Venereol 2012; 26: 36-40.

25 Vicentini C, Vignion-Dewalle A, Thecua E et al. PDT of AK with the Aktilite CL128: irradiance distribution and impact of light dose on the treatment efficacy. EuroPDT Nice 2018.

26 Halldin CB, Gillstedt M, Paoli J et al. Predictors of pain associated with photodynamic therapy: a retrospective study of 658 treatments. Acta Derm Venereol 2011; 91: 545-51.

27 Kim BS, Kim JY, Song CH et al. Light-emitting diode laser versus pulsed dye laser-assisted photodynamic therapy in the treatment of actinic keratosis and Bowen's disease. Dermatol Surg 2012; 38: 151-3.

28 Tarstedt M, Rosdahl I, Berne B et al. A randomized multicenter study to compare two treatment regimens of topical methyl aminolevulinate (Metvix)-PDT in actinic keratosis of the face and scalp. Acta Derm Venereol 2005; 85: 424-8.

29 Farhi D, Bedane C, Savary J et al. The France-PDT study: a national prospective observational cohort survey on the use of methyl-aminolevulinate photodynamic therapy in France, with up to 6-month follow-up. Eur J Dermatol 2013; 23: 68-76.

30 Kessels JP, Nelemans PJ, Mosterd K et al. Laser-mediated Photodynamic Therapy: An Alternative Treatment for Actinic Keratosis? Acta Derm Venereol 2016; 96: 351-4.

31 Vicentini C, Carpentier O, Lecomte F et al. Treatment of a vulvar Paget's disease by photodynamic therapy with a new light emitting fabric based device. Lasers Surg Med 2017; 49: 177-80. 